Dr. Nol.AN thanked Dr. O'Doherty for his paper and said that he considered patients in the Omagh Asylum were particularly fortunate in having s!ıch a careful observer and skilful physician to attend them.

The PRESIDENT paid a warm tribute to the efficient manner in which this severe epidemic had been dealt with by the staff of Omagh Asylum.

Dr. O'DoHerTy thanked the members for their reception of his paper and replied to the various points raised in the discussion. He stated that he set great value on the Widal reaction when confirmed by other tests. The drains at Omagh Asylum had been recently laid but jointed with Portland cement, which had cracked, causing leakage. Medina cement was now considered better than Portland for this purpose.

Dr. Plummer exhibited scissors which he had designed for possible use in asylums. The points were blunt, and by a blocking arrangement at the joint the scissors could only be opened sufficiently to allow of thin material being cut. Dr. Plummer stated that he was engaged upon the construction of a better working model.

Dr. Hetherington hospitably entertained the Division at luncheon.

The PRESIDENT proposed the health of Dr. Hetherington, and thanked him for the hospitable manner in which he had entertained the Division at Londonderry ; the toast was most cordially received by the members present, and Dr. Hetherington returned thanks in a kindly appreciated speech.

After luncheon, the members, under the guidance of Dr. Hetherington and

his staff, visited the New Branch Asylum and spent a most enjoyable afternoon.

\title{
THE ANNUAL DINNER.
}

The Annual Dinner was held on Thursday evening, in the Guildhall, and there were about seventy present. Dr. Soutar presided. Among the guests were the High Sheriff of Gloucestershire (Mr. Jenner Fust), the Deputy-Mayor of Gloucester (Mr. Bruton), Mr. Hyett (Chairman of Quarter Sessions), Mr. Colchester-Wemys; (Chairman, County Council), Mr. E. S. Hartland, and Mr. Sheffield Blakeway.

The Toasts.

ThF. King.

The President, in submitting this toast, stated that wherever Britons were gathered together it was sure, without a word from the proposer, of being received with acclamation.

The Queen, Quefn Alexandra, thf Prince of Walfs, and the Rest of the Royal Family.

The President next proposed this toast, pointing ont how their Royal Highnesses had added dignity to their high estate by the interest they always took in the joys and sorrows of the people, by which means they had won for themselves the love of the nation. The toast was musically honoured.

The Medico-Psychological Associntion of Great Britain and Ireland.

The High Sheriff of Gloucestershire (Mr. Jenner Fust) said that when he was invited to be present at this gathering he esteemed it a very high honour, and he did not think there was an honour still higher in sture for him, namely, to propose success to the Association. The history of the Association was well known to those who were connected with it, but for the benefit of those who were not members of it, but were partaking of its hospitality, he might observe that, like many other great things, it had its origin in small beginnings. About seventy years ago a few gentlemen met together occasionally, at each other's houses, in order to discuss points of interest in respect to the care and treatment of the insane. They derived considerable benefit from that interchange of opinion, and they were 
naturally anxious that others should participate in it. Hence came additions to the numbers associated with it, and an enlargement of the sphere of operations, until there was now a membership of over 700 . Its operations extended over the whole of Great Britain and Ireland, and he was told that its influence was felt to the remotest end of the British Empire. Not only so, but foreign countries had considered it wise to adopt the methods and the constitution of the Association as a model for their own guidance. In Gloucestershire they were familiar with a somewhat similar instance of large results from small beginnings. It was now forty or fifty years since a few chairmen of boards of guardians met together at Hardwick Court, not many miles from where they were now assembled, at the invitation of that well-known philanthropist, Mr. Baker, to talk over points connected with the Poor Law. They found very great advantage from that interchange of opinion, and they sought to extend the usefulness of those conferences. The result had been that the whole of England and Wales had been, for many years past, mapped out into districts, each of which held its own conference once a year on Poor Law matters, and each sent representatives to a central conference in London, which had grown to such an extent that the council chamber of the London Guildhall was not large enough to accommodate those who were anxious to be present. These two cases were somewhat parallel, and were also alike in being instances of what he regarded as one of the glories of this country, namely, the enormous amount of work which gentlemen were willing to do voluntarily and without any hope of reward for the general good of the community. The objects of the Association were well known, and they had been briefly stated to be improving the general condition of patients, and to encourage the more advanced administration of asylums. With those objects in view the Association had encouraged the careful study of the scientific aspects of insanity. They had spent a vast amount of time and labour in training nurses, some thousands of whom had been examined and certified after a course of training. Above all, the Association had laboured to demonstrate that insanity was a definite disease and demanded strict medical treatment in all its phases. But he must not pursue that line of thought or he would speedily get out of his depth. However, assuming that insanity was a definite disease which had to be dealt with, it was interesting to think how far the system obtaining in this country succeeded in supplying the want. Was our system one by which anyone attacked by that definite disease could be sure of receiving the treatment most likely to result in the cure of the patient? He feared that, in spite of all that had been done, the answer could not be altogether in the affirmative. That was not the place to enter into details, but he would like to say that what we seemed to lack, and what we ought to have, was one strong central authority charged with the care of the whole of the cases of mental deficiency or mental aberration from the case of "Simple Susan" to that of the dangerous homicidal maniac. Such a body could, no doulit, work through local authorities acting over a large area, at least the area of a county, and possibly even a larger area; and it might avail itself of all the existing machinery while having the power to supply what more might be found to be required. He therefore pleaded for a large central authority, and he confessed he regretted the proposals which had been made in the Mental Deficiency Bill which was now before the Houses of Parliament, and which sought to set up a new body of Commissioners, acting independently of other bodies, and charged with the care of the class usually spoken of as feeble-minded. Surely that class was only part of a much greater whole, which ought to be dealt with by one sole authority. In submitting the toast of the Association he wished it God-speed in its work of endeavouring to ameliorate the condition of what was perhaps the most pitiable class of the whole community. He coupled with it the name of the President, Dr. Soutar.

Dr. Sout AR (President) expressed his thanks to Mr. Jenner Fust, on behalf of the Association, for the favourable appreciation he had given utterance to, and for the hopes he had expressed for the Association's continued prosperity and success. He also thanked his hearers for the hearty way in which they had responded to the happily worded sentiments of the High Sheriff of the county. Earlier in the day, and speaking to a somewhat different audience, he mentioned that the Association originated in Gloucester seventy-one years ago-it would be seventyone years on the $27^{\text {th }}$ of this month. So that in addition to the very powerful body to which the High Sheriff alluded, the Medico-Psychological Association 
was a Gloucester institution. He did not wish to dwell too much upon that lest "the stranger within their gates"-for by right of settlement in the county he claimed to be a Gloucester man-should assume there was, mixed up with pride at the circumstance, a sense of surprise that anything so great and useful as their Association should have originated in the county. He assured the company there was no reason for any such suspicion. On the contrary, they believed that the reason for the extraordinary vitality and vigour of the Association was to be found in the fact that it was born and cradled in the county of Gloucester. He did not wish to pursue that subject too far, but merely to indicate that these qualities were strongly in evidence very early in the Association's career. For, in its early days, it withstood a shock such as had proved the undoing of a large number of youths and youthful enterprises. It was absolutely discarded and disowned by its parent. That interesting episode in the Association's history would perhaps bear re-telling. Dr. Hitch, who was superintendent of Gloucester County Asylum in 1841, was the parent of the Society, and he took very great interest in its doings. Suddenly it was noticed that he ceased to do so, but no explanation of the change of attitude was given. He simply ignored it. Men wondered, but could not understand why the change had come about. The good Dr. Hack Tuke, who was a friend to many outside the Community of Friends, to which he belonged, determined that he would, if possible, unravel this mystery. He approached Dr. Hitch tactfully, found that he was injured in his feelings, and that the wound had been inflicted by a President who was occupying the position which he, Dr. Soutar, now occupied, at one of the annual gatherings. Looking at the company who had done justice to the good things before them, and carried away by the social success of the evening, he jumped to the conclusion that the Society had been to the festive manner born, and declared that it had come into being at a convivial assembly at the Gloucester County Asylum. That reference hurt Dr. Hitch very much indeed. Some might think it was stupid of him to take notice of what a President called upon to make an after-dinner speech might say. He might have remembered that great men and great enterprises had first seen the light in very queer places. Dr. Hitch was not a philosopher, he was a parent, and parents were proverbially touchy when things were said about their offspring. Dr. Hitch, instead of doing what most others would probably have done, namely, "gone for", the President who had made the statement, simply ignored his child. But it should be remembered that when feelings are hurt, conduct might be very erratic. His child had been branded as the product of conviviality. Dr. Hack Tuke, being a true conciliator, did not pooh-pooh his feelings, but he understood, and entered into them. As a great lover of historical accuracy, he published the necessary correction that the Society came into being only after a prolonged and tedious labour of two days. This at once satisfied Dr. Hitch, his pride in his infant was restored, and he resumed his paternal interest in the Association. He, Dr. Soutar, believed that the first to wish the young society success were the Committee of the Gloucester County Asylum; and that sympathetic interest on the part of laymen with whom members worked had continued down to the present day. Most of those present owed it to their Committees that their difficulties were diminished and their purposes were promoted. As an Association, they had again and again been welcomed by laymen eager to show their interest in the work. It was delightful to come back to Gloucestershire and find that the spirit which actuated the Committec of the Gloucester County Asylum over seventy years ago still moved the laymen of the county to-day. The Corporation of the City had shown their interest by placing at the disposal of the Association the Guildhall for their mectings and for this dinner, and amongst those now honouring the Association by their presence were some who were most prominent in the public work of the county and the city; and they had joined with the High Sheriff of the county in expressing their hopes for their continued well-being, and in recognition of the work which, so far, they had been able to do. In the name of the Association he thanked them.

The City of Gloucester.

Dr. Hayes Newington proposed the toast, "The City of Gloucester." He said it must have been in a very giddy and heedless mument that he surrendered 
to the President's suggestion that he should accept the responsibility of proposing the toast which had been allotted to him. But at the time he remembered well the many happy days he spent not far from that city, and thought that memory would provide some inspiration as to what he should say. It was at a spot between the Fcrest of Dean on one side and the glorious Severn on the other where, as a boy fifty years ago, he spent those days. It was a land which flowed with ginger-beer-home-made-figs, grapes, and everything which a boy could desire, with an occasional hornet to remind one of the mutability of human affairs. It was his custom to visit the city and go to the cathedral to hear $\mathrm{Dr}$. Wesley's glorious music, and sometimes to see the old Mop Fair, which had now been removed from the city; and occasionally to buy tobacco and a little pipe, wherewith to indulge himself surreptitiously-one could not sin in cigarettes at that time. But when he came to consider all these matters, he found, as a pyschologist, it was impossible to transmute such emotions into anything like a suitable basis for this toast. So he had to go to history. But to-night he found that he had misread his history. He had an idea that Gloucester was started by some of the cheap trips run by the Danes and Saxons of the time. But Mr. Waller had just told him that the Romans had left a very comfortable city for these cheap trippers to stop in, and they stopped. A study of the whole question led him to deduce two things: First, that Gloucester stands where it did; and secondly, that it had stood in that spot a tremendously long time. And from there it was reasonable to further deduce that it would stay there for a long time yet. But by "standing" he did not mean standing still, because one saw evidences all round in many ways of advance. Even in his short time he could see that the city had improved greatly. And he thought one might take that great hall in which they were dining, with the spacious and very comfortable offices attached to it, as evidences of betterment, because he was sure the Romans did not build them. He would like to embrace the opportunity of unofficially offering a particularly hearty vote of thanks from the Association to the Corporation for kindly allowing the use of the hall. They would be the recipients of an official vote of thanks in due course. He could say with absolute certainty that the tedium, if there were such attached to a meeting of this kind, was enormously relieved by such a reception as they had had. He coupled with the toast the name of the Deputy-Mayor of Gloucester: "May Gloucester thrive for ever, and may those who take such great care of it, live for ever !"

The toast was heartily pledged.

The Deputy-Mayor of Gloucestre (Mr. Bruton), in replying to the toast, said he much regretted the absence of his Worship the Mayor, because if he had been present to respond to the toast he would have spoken with much greater authority than he himself could. But on behalf of the other members of the Corporation he wished to thank the proposer of the toast for the kindly reference he made to the city authorities, and to assure Dr. Newington and the other members of the Association that it was with the greatest possible pleasure that the Corporation acceded to the request to place the Guildhall at the disposal of the Association for its meeting. The Treasurer said he did not believe the Romans built that hall. It was true, but it was erected on the site of the old Roman pratorium, so that even in that respect the connection with their forefathers was maintained. They were very proud indeed of this old city, which was full of historic interest and antiquarian lore, and those whose bent was that way could indulge it to any extent. So far as the commercial side was concerned, their merchants were enterprising, and the tradespeople were up-to-date; and although they did not experience those waves of prosperity which were known as "booms," yet, on the other hand, they did not have those great periods of depression which visited most places in this country. With regard to the Corporation, he thought the success which it had so far achieved was mainly owing to the fact that so many members of the medical profession joined its ranks. He would not detain the gathering longer, because if an antiquarian discussion were to be started with the Treasurer, more time would be occupied than could be spared; but they were very proud of all their buildings in Gloucester, and especially the Royal Infirmary. And the citizens were proud of the medical profession, whose members unstintingly gave their services on behalf of that noble institution. In thanking the Association for its generous hospitality, it was a matter of great interest to hear of the birth of the Association 
having taken place in the City of Gloucester. He was sorry to hear there was a little disagreement afterwards, and that might account for the long period which had elapsed before the Association revisited its birthplace. It reminded him of the familiar phrase in the "agony" column, "All is forgiven, come home at once." (Laughter.) He expressed the hope, after what had been said about Gloucester, and the pleasure which had been experienced from the visit, that the City might have the honour, at no very distant date, of welcoming the Association again.

\section{ThE Visitors.}

Sir Grorge Savage, in proposing this toast, said he had much pleasure in supporting his friend, Dr. Soutar, in any way he could. The Association had great pleasure in receiving its guests; they knew the interest which the world at large took in its aims at the present time. It was felt that we were now at the turning point. There was a time when the lunatic was simply someone who had to be shut up. That was followed by a time when he had to be shut up and looked after kindly. But now every attention was concentrated on how he was to be cured; and one felt that the meeting of the Association was but one step forward in that great work, for in every direction the question was asked, not only how could insanity be cured, but how could its increase be checked? The question of the feebleminded and the Bill which had been promoted for dealing with them was one of immense importance, although he was free to confess that some went too far. A short time ago he took the chair at a drawing-room meeting on this subject, and he was obliged to sum up in the end in this way: "It seems that many of you who have spoken to-night think that everything that is foolish and eccentric should be removed. If the world were to be deprived of everything that was eccentric, if all the eccentrics and the fools were to be segregated, the world would be very uninteresting, and it would be a place scarcely worth living in." It must be remembered that there was an intolerance of suffering in our friends and a tendency to get rid of them; and he felt that such a tendency was not to be encouraged too much. He was sure their guests would appreciate the work which the Association was doing and trying to do, and he had much pleasure in associating with the toast the names of two gentlemen, Mr. Hyett, Chairman of Ouarter Sessions, Chairman of the Education Committee and Chairman of Barnwood House, and Mr. Colchester-Wemyss, Chairman of the County Council. There were guests present who were not medical men, but who were working with them, and one felt that in all the large hospitals in London the greatest work was being done by the cooperation of the laymen with the doctor. Let there be no jealousy. One felt that chairmen were a power, and such power as was exercised by the gentlemen he had named he felt sure could be for nothing but good.

Mr. F. A. Hyetr thanked the company for the reception they had accorded to the toast. Like the High Sheriff, he esteemed it a great honour to have been included among the guests, and he was proud to welcome the Association to Gloucester. His pride was enhanced by the fact that the President, Dr. Soutar, acknowledged that he was one of the Gloucester people. Still further was his satisfaction enhanced by the statement, which he was not previously aware of, that the Association was born in the City of Gloucester. The High Sheriff had described the different objects which had combined to call the Association into existence. The first of those objects was doubtless appreciated by all the world. In his few remarks he proposed to touch on only the third, namely, research into the causes of insanity. Of course the scientific and those who had any pretence to culture fully realised its value, but he did not know that it was adequately appreciated by all sections of the public. As the High Sheriff hinted, some were alarmed at the name " research." and he knew that even intelligent, practical men of business were a little shy of the subject. He remembered an anecdote concerning the period of his childhood which seemed to illustrate that view of the subject by a section of the public. It would be remembered by some that the arrangements for the 1851 Exhibition,were made by a committee, presided over by the Prince Consort, or, as he then was, Prince Albert. The Prince, in his opening remarks, said he thought it would be convenient if the business were conducted under two categories. A subsequent speaker, who was a London merchant, commented on the phrase, and 
said he hoped the Prince was not going to introduce German metaphysics into the discussion. He, Mr. Hyett, congratulated the members of the medical profession on the importance of their work. That, perhaps, was not a great compliment, as there was so much work of importance. Indeed, he thought that anyone to whom public work was entrusted had much to be congratulated upon, except, perhaps, Chancellors of the Exchequer. But he congratulated members of the Association on their work because of its special character. It embraced such a large field. So much had been achieved in the fields which the explorer traversed that sometimesperhaps erroneously-one was inclined to think there was not much more to be found out or to be done. We had seen the dreams of Leonardo de Vinci become accomplished facts; sights and sounds which, in their essence, were evanescent, we had seen imprisoned and made capable of frequent repetition, not always to the advantage of those who took their pastime on the river. We had seen the spots on the earth's surface which were not capable of accurate delineation getting less and less and rapidly disappearing. The work of the specialty now represented was not of that character. Unlike the work of Sir Samuel Baker, a Gloucestershire man, they had nothing to do with tracing rivers to their source; it was for the medical men present to examine the springs of thought; their work lay in that dim realm where mind and matter meet-at present an almost unknown country. What tremendous possibilities were before the specialty! Who would venture to predict the nature of the discoveries which they might make? But he felt they might rest assured that in their labours to reduce mental and physical suffering it might very well be that they would make additions to the sum of human knowledge which would necessitate the reconstruction of ethical systems and the revision of creeds. He thanked the company for the reception given to the toast.

Mr. Colchester-Wemyss (Chairman, County Council) also responded. $\mathrm{He}$ said that a friend of his, who was addicted to the pernicious habit of reading the daily newspapers, and to whom he imparted the fact that he had been invited to this dinner, assured him, the speaker, that he was undergoing a serious risk. From his study of the newspapers, that gentleman believed there was a sort of volcanic eruption going on in the medical world at the present moment, and that if he, $\mathrm{Mr}$. Colchester-Wemyss, trusted himself into an assemblage of doctors nobody could be answerable for the results. He, however, decided to go through the ordeal, and he had had no reason to regret the decision. So far as he could see the visitors had been received with every urbanity and courtesy, as well as with all possible hospitality. In fact, as far as his experience of the members of the Association was concerned, it appeared to him they might be correctly described as "the mildest mannered men who ever scuttled ship or gouged an eye." On behalf of the visitors, especially those who belonged to the county of Gloucester, he wished to express their great gratitude for the hospitality received, and the earnest hope that the Association's experiences of the ancient and interesting rity of Gloucester, and the picturesque county of that name, would be such that the members would be tempted, long before such an interval as that since 1841 had elapsed, to return to that city and county.

The President.

Dr. Needham said he had been asked to propose the next toast, and he felt it a great honour that the request had been made. He regarded that as the toast of the evening. It was the toast of the health of the President of that great Association, Dr. Soutar. (Applause.) The toast was evidently a popular one, from the applause, and he proposed it with the greatest possible pleasure. It enabled him to express, on behalf of his colleagues who were not able to be present, their great regret that they could not be among them, and their best wishes for the success of Dr. Soutar during his year of office, and of the Association generally, in which they took the keenest interest. He was also glad to propose the toast as a token of his deep and sincere regard for Dr. Soutar, with whom he had been on terms of warm intimacy and friendship for nearly thirty years, during nine of which they were colleagues. $\mathrm{He}$ and the present company knew enough of Dr. Soutar to feel sure that the honour and dignity and the influence of that great Association would suffer no depreciation during his presidency. He would ask them to drink very heartily to Dr. Soutar's good health and great success and prosperity during his year of office. 
Dr. Soutar, in reply, said this was just one of those occasions when "ordered words asunder fly," and one found oneself unable to give expression to the ideas which were pressing each other in one's mind. To have had his health proposed in such kindly terms by Dr. Needham was an honour and a delight to him, such as he could not express. He looked back to his time with Dr. Needham as being that to which he owed any success which he had had in life, and it was that which placed him in his present position that day. To have had the advantage, in the plastic and mouldable years of life, of coming under the influence and example of Dr. Needham had given to him everything to which he, in his professional life, had attained. He could only thank Dr. Needham most sincerely for the friendly and kindly expressions he had used towards himself, and the company for the kind way in which the toast had been received.

\section{MENTAL DEFICIENCY BILL.}

Select Committee of the Parliamentary Committee of the MedicoPsychological Association of Great Britain and Ireland.

W. R. Dawson, H.M. Inspector of Lunatic Asylums, Ireland; Ex-President Medico-Psychological Association.

J. G. Soutar, Medical Superintendent, Barnwood House; President MedicoPsychological Association.

Theo. B. Hyslop, late Senior Physician, Bethlem Royal Hospital (Chairman).

Harry Corner, Consulting Physician to the National Association for the FeebleMinded.

G. E. Shuttleworth, late Medical Superintendent, Royal Albert Asylum.

R. L. Langdon Down, Consulting Physician to National Association for the Feeble-Minded.

F. W. Turner, Assistant Superintendent, Royal Eastern Counties Institution.

H. Hayes Newington, past President, Medico-Psychological Association.

J. Carswell, Certifying Physician in Lunacy, Parish of Glasgow.

$\mathrm{H}$. Wolseley-Lewis, Superintendent of the Barming Heath Asylum, Kent.

Bedford Pierce, Medical Superintendent, The Retreat, York.

Report of the Select Committee to the Annual Meeting appointed to consider the Mental Deficiency Bill.

Fune 16 th, 1912.

Your Committee has held three meetings, and has carefully considered the Bill clause by clause and has to report as follows :

The kernel of the whole Bill lies in Clause 17, defining the persons subject to be dealt with by the Bill, and it must be borne in mind that such persons must come under both sections $(\mathrm{I})$ and (2). On examination it will be seen that the subsections $(a)$ to $(f)$ and $(a)$ to $(e)$ are so framed as to include a very wide range of mental defectives, embracing habitual criminals, inebriates, the uneducable, the unemployable, the subjects of drug habits, and persons unfit to procreate. While agreeing with the inclusion of such persons in the Bill from a general standpoint, your Committee feel that the subclauses are too vaguely worded, and that further definitions are needed, particularly in regard to section ( 1 ) (e), dealing with those who are to be deprived of the opportunity of procreating children.

Your Committee are also strongly of opinion that the Board of Control, whether in the Secretary of State's or other Government department, should have as its first members the present Lunacy Commissioners, and have altered the Bill in accordance with this view.

Your Committee recommend that the following alterations be made :

Clause 2 (I): Delete from "any" (line 23) to "recommendation" (line 25) and substitute " \& Board of Control and the first members of such Board shall be the persons who at the commencement of this Act are the Commissioners in Lunacy together with persons (one of them being a woman) to be appointed by the Secretary of State who may." Line I, page 2 : Delete "Provided that one" to "woman." (5), line is : . Delete " not exceeding three."

LVIII. 